coveries of Watt, Peaucellier, Tchebycheff, Sylvester, Hart, and Kempe ; also examples of Sylvester's and Kempe's isoclinostats. These last models are made, some in zinc, but most of them of printer's rules, the articulation being effected by brass pipes. We close our recollections of this section with the bare mention of an ingenious application of the zoetrope to illustrate certain mechanical combinations in motion.

In the engineering department was a collection of elementary plane mechanisms as described in Prof. Kennedy's translation of Reuleaux's " Kinematics": links, made as before of printers' rules ; cylinder-pair of brass pipes, prism-pair of wood and brass allowing any joint to be fixed, and a complete motion, all the motion truly complane; also a contrivance used for fixing a link when its plane of motion is between two others. Among instances of other mechanisms given in Reuleaux, we noted a duangle moving in a triangle, triangle in a square, \&c. ; models of glass, centroids stuck on them, so making the conception clear; several examples of spherical quadrilaterals made of zinc. Here also we mention the model of a steam-engine excentric, showing the reversion of motion.

Among matters in preparation we examined with interest a pendulum apparatus which presented some novel features, but it would take too much space to dwell further upon what we saw under the courteous guidance of M. Robin. What we have said-and here we acknowledge our indebtedness to the superintendent's clear exposition, and to a short account of some of the models given in "Engineering" for June 1 5, I 877, descriptive of the scientific objects exhibited at the professor's conversazione-will sufficiently indicate the way that has been made in the short space of one year, under the careful supervision of the professors. Very many of the models are the work of the students. We had not time to examine the physical section, which is devoted to the construction of simple physical apparatus.

\section{THE SETTLE CAVE EXPLORATION}

TH

E Settle Cave Exploration Committee have again nearly exhausted the funds at their disposal, and are preparing a statement of accounts and a fresh appeal to the public.

The great thickness of beds already excavated in the Victoria Cave has taken us down so far into the past that it would be a thousand pities to close the work prematurely before getting down to the cavern floor. But unless the Committee receive help soon they will be obliged to stop and leave the rest of the cave's history in obscurity. We have appealed to our readers in behalf of this important undertaking before, and we are sure we shall not do so in vain again. There must be many readers of NATURE interested to see the final results of the exploration of these interesting caves, and who are at the same time able and willing to give substantial help to the Committee. We are sure the smallest contribution will be thankfully received, and we trust the Committee will, without delay, be encouraged and enabled to continue their researches. The Treasurer, Mr. John Birkbeck, junr., will receive donations at the Craven Bank, Settle, Yorkshire.

ORGANISATION OF FRENCH METEOROLOGY

$\mathrm{N}$ May 7 the Academy of Sciences adopted in its secret meeting the draft of a letter to $M$. Bardoux, the Minister for Public Instruction, asking him to state whether he was to establish a separate administration for meteorology or continue the existing system. The answer to this was considered as an essential preliminary to the selection of the candidates for the directorship of the Paris Observatory. The candidates have not been nominated yet, "but a definite answer has been given to the Academy of Sciences. The decree organising the meteorological division of the observatory into a distinct service was signed by the president on the I 3 th and gazetted on the 14th. It is prefaced by a summary of the several steps taken by Leverrier (whose name has been carefully omitted) to give the meteorological organisation its existing form.

The decree can bardly be considered as an innovation, and may be more aptly termed a resuscitation of a former stage in the evolution of official meteorology in France. In i 864 Leverrier had under him three subordinates: one was the head of the warning department; M. Rayet, the head of that which investigated general movements of the atmosphere ; and the third M. Sonrel, the head of meteorological stations, their inspector, and general computer. M. Sonrel having died and M. Rayet having resigned, their offices were suppressed for the sake of economy. The whole of the work was executed on a reduced scale by subordinates. M. Bardoux has recalled into existence these two services, which are styled "Study of the General Movements of the Atmosphere " and "Climatology with Inspection of Meteorological Stations." The head of these two services will be a meteorologist, and one of the three meteorologists will be appointed director of the Central Bureau.

This appointment will not take place immediately, as the advice of a special council of the Central Bureau must be taken by the Minister. This council will be formed of members of the Institute and the large public administrative departments - Telegraphy, Admiralty, Public Instruction, War Office, \&c., connected in any way with meteorology.

The greatest innovation is the authority given to the Central Bureau over the several meteorological observatories which have been established or will be established in the various districts of France, either at the expense of Government, of departments, or of townships. The more important of these observatories now in existence are Montsouris (Paris), Lyons, Puy-de-Dôme, and Pic du Midi. It is not stated whether the decree will extend to Algerian observatories, which publish a special journal and have their observations taken with a special system.

The Bureau Central will be in direct communication with the departmental commissions which M. Leverrier has established in almost every department. Each of these commissions will have the control of the agricultural stations in its own district. If the president requires it, he will receive franco a daily telegram to help him to issue special warnings, as the practice is daily gaining ground. In many parts of France departmental commissions have been grouped into regional organisations according to the initiative taken by Leverrier. The directors of regional meteorological observatories, delegates of regional commissions, and delegates of the Meteorological Society of France, meet once a year to deliberate on topics of interest for the progress of meteorology. The Meteorological Society is a free society supported by voluntary contributions. It is the first time that such a body has been endowed with official privileges.

The departmental commissions, although established mostly by the prefect and the local engineers of the Ponts-et-Chaussées, are supported by private exertions and contributions, as well as donations from departments and townships. M. Leverrier established an observatory in each normal school in France (there is one normal school in each department). All these observatories are to be visited by the delegates of the Bureau Central and their observations published by it. These normal school observatories will issue warnings for their localities. Some of them have already begun.

The Champ de Mars meteorological pavilion contains. a number of valuable documents already sent by normal schools and departmental commissions, whose exertions will be regulated under the new system. 